\title{
A Study of the Diphenylamine Test for Aliphatic Nitrocompounds
}

\author{
Kivi Grebber and J. V. Karabinos*
}

\begin{abstract}
A study has been made of the diphenylamine test for aliphatic nitrocompounds. It is not given by all nitroparaffins. However, the test is at least a thousand times more sensitive than previously supposed. Structural factors are discussed.

Spectroscopic measurements indicate that the blue color in the diphenylamine test with nitrosating agents is similar to that produced by oxidizing agents. It is probably caused by colored phenazine and benzidine derivatives. A possible free radical mechanism for the reactions involved is presented.
\end{abstract}

\section{Introduction}

The blue color that has been obtained by the action of nitrosamines, nitrates, nitrites, and aliphatic nitrocompounds on diphenylamine in sulfuric acid has been regarded $[1]^{1}$ as a specific test for these substances in the absence of various oxidizing agents that also produce a blue color. In view of the fact that certain nitrocompounds did not give this test, a reinvestigation with pure aliphatic mono- and polynitrocompounds seemed in order.

The nature of the blue color itself has been the subject of investigations by Wieland [2, 3] and Kehrmann [4, 5] and their coworkers, but evidence about the structure of the colored products has been incomplete. It therefore seemed desirable to obtain spectroscopic evidence as to the nature of the colored products.

\section{Experimental Details}

\subsection{Reagents and Materials}

a. Sulfuric acid solution (approximately $29 N$ ) was prepared by adding 4 volumes of sulfuric acid (approximately $36 \mathrm{~N}$ ) to 1 volume of distilled water.

b. Diphenylamine reagent was prepared daily by dissolving $20 \mathrm{mg}$ of recrystallized diphenylamine in $100 \mathrm{ml}$ of warm $29 \mathrm{~N}$ sulfuric acid solution.

c. Aliphatic nitro compounds, some of which were laboratory preparations and others commercial products, are listed in table 1.

d. N-Nitrosodiphenylamine, mp $67^{\circ} C$, was obtained by nitrosation of diphenylamine [6].

e. Tetraphenylhydrazine was prepared by oxidizing diphenylamine with lead dioxide [7].

f. $N, N^{\prime}$-Diphenylbenzidine, $\mathrm{mp} 238^{\circ} C$, was prepared by rearrangement of tetraphenylhydrazine with sulfuric acid [7].

g. $N, N^{\prime}$-Diphenyldihydrophenazine, $\mathrm{mp} 170^{\circ} \mathrm{C}$, was obtained by refluxing tetraphenylhydrazine with toluene [2].

*Present address, Blockson Chemical Co., Joliet, IIl.

1 Figures in brackets refer to references at the end of this paper.
TABLE 1. Results of the diphenylamine test for aliphatic nitrocompounds

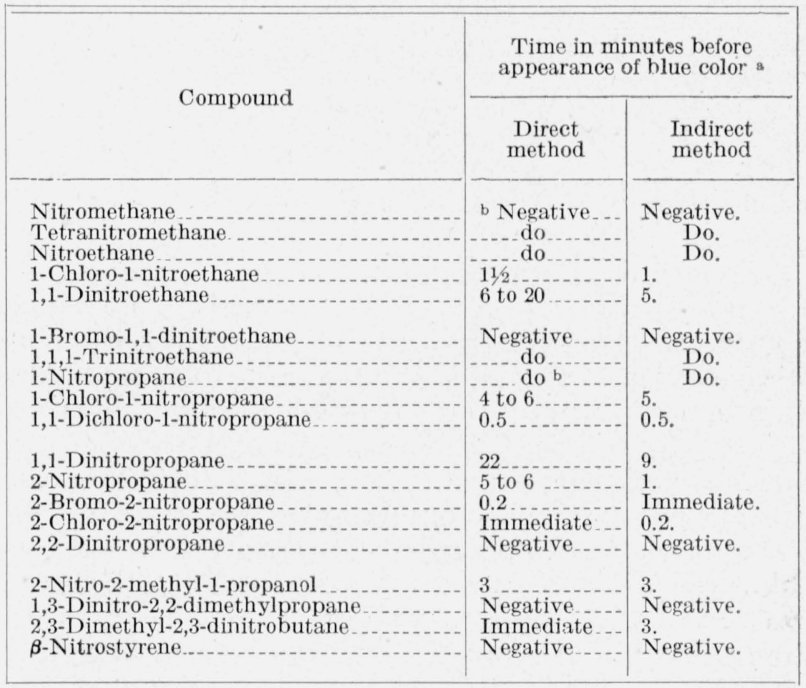

a A test was regarded as negative after $1 \mathrm{hr}$. It is evident that the time required for the formation of the blue color would be dependent upon various factors, including purity and structure of the substance.

b The unpurified sample gave a positive test with $1 \mathrm{mg}$ of nitrocompound.

\subsection{Performance of the Diphenylamine Test with} Pure Aliphatic Nitrocompounds

\section{a. Direct Method}

Ten microliters of liquid or $10 \mathrm{mg}$ of solid nitrocompound was dissolved in $10 \mathrm{ml}$ of the sulfuric acid solution, and $10 \mu$ liters of the resultant solution was added to $1 \mathrm{ml}$ of diphenylamine reagent. The test tube containing the mixture was maintained in a boiling water bath (approximately $98^{\circ} C$ ) for $1 \mathrm{hr}$. The time required for the appearance of a blue color is recorded in table 1. Although a test was regarded as negative if no blue color was observed within $1 \mathrm{hr}$, actually in such cases no blue color appeared even after $8 \mathrm{hr}$. With nitrocompounds which give a positive test the lower limit of sensitivity seemed to be in the neighborhood of $1 \mu \mathrm{g}$. 


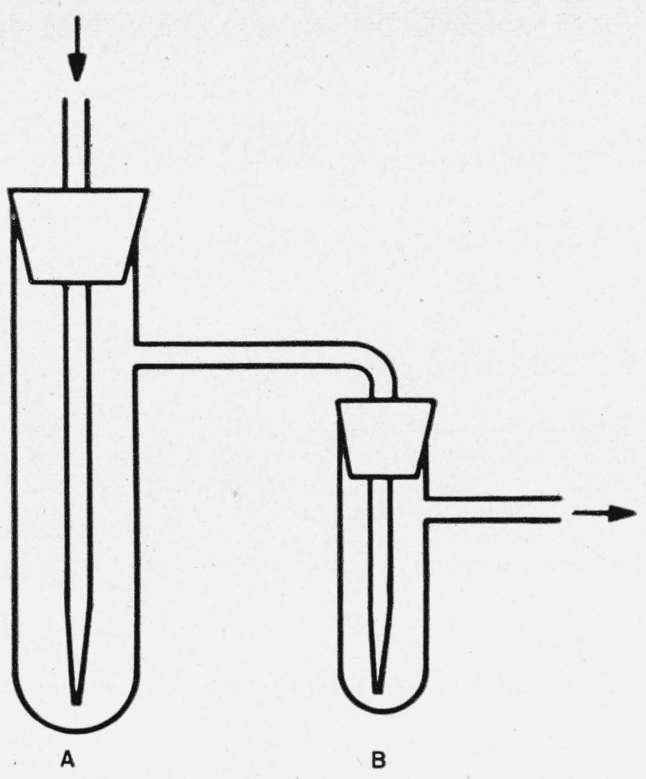

Figure 1. Gas evolution apparatus.

\section{b. Indirect Method}

In tube A of the apparatus, figure 1, was placed $10 \mathrm{mg}$ of solid or $10 \mu$ liters of liquid nitrocompound and $2 \mathrm{ml}$ of the sulfuric acid solution. Tube $\mathrm{B}$ contained $2 \mathrm{ml}$ of diphenylamine reagent. The apparatus was maintained at $98^{\circ} \mathrm{C}$ for $1 \mathrm{hr}$ while a slow but continuous stream of air was allowed to flow through the system. In a blank determination, the air did not show oxidizing effects. As before, a test was again regarded as negative if no blue color was observed in tube B within $1 \mathrm{hr}$. The results are recorded in table 1 . The test performed in this manner required more than $1 \mathrm{mg}$ of nitrocompound.

\subsection{Isolation of $N$-Nitrosodiphenylamine formed in the Diphenylamine Reaction}

In tube $\mathrm{A}$ of the gas-evolution apparatus (fig. 1), maintained at $98^{\circ} \mathrm{C}$, was placed $500 \mathrm{mg}$ of $2,3-$ dimethyl-2,3-dinitrobutane and $5 \mathrm{ml}$ of the sulfuric acid solution. Fifty milligrams of purified diphenylamine, dissolved in $5 \mathrm{ml}$ of ethanol, was placed in tube B, which was surrounded by an ice bath. Air was passed through the apparatus at a moderate rate for $1 \mathrm{hr}$. The solution in tube B was diluted with water to turbidity and refrigerated overnight. The yellow crystals, after recrystallization from pentane, melted at $66^{\circ}$ to $67^{\circ} \mathrm{C}$ and did not depress the melting point of an authentic sample of $N$-nitrosodiphenylamine $\left(\mathrm{mp} 67^{\circ} \mathrm{C}\right)$.

\subsection{Spectroscopic Study of the Blue Color}

Solutions containing $8 \mathrm{mg}$ of the following substances were prepared with $100 \mathrm{ml}$ of diphenylamine reagent and allowed to stand overnight at room tem-

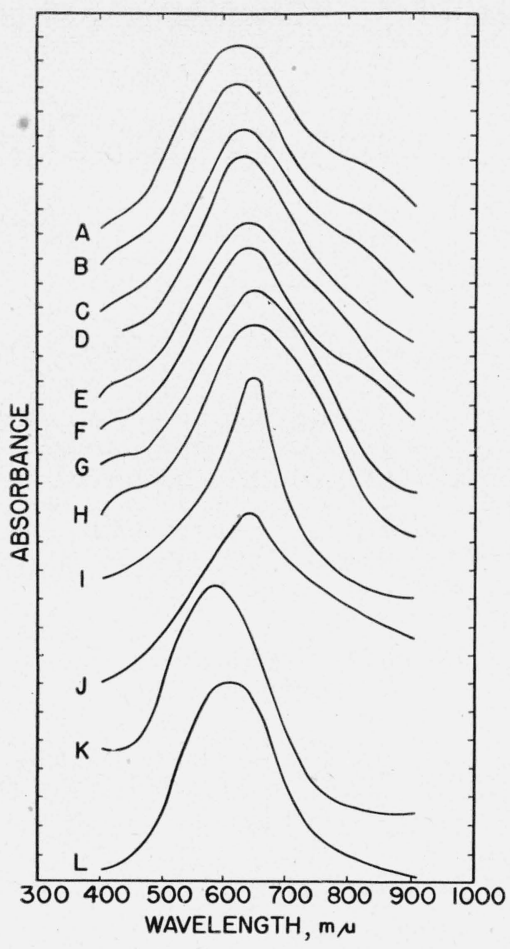

Figure 2. Some absorption curves related to the oxidation and nitrosation of diphenylamine.

perature; A, sodium nitrite; $\mathrm{B}$, potassium nitrate; $\mathrm{C}$, 2,3-dimethyl-2,3-dinitrobutane; D, $N$-nitrosodiphenylamine; E, hydrogen peroxide; F, 1,1-dichloro-1nitropropane; G, sodium chlorate; H, 2-nitropropane; I, tetraphenylhydrazine; J, $N, N^{\prime}$-diphenyldihydrophenazine + sodium nitrite; $\mathrm{K}, N, N^{\prime}$-diphenylbenzidine + sodium nitrite; L, J+K (1:1).

Substances D, I, J, K, and L, however, were dissolved in $29 N$ sulfuric acid solution containing no diphenylamine. The deep-blue solutions that resulted were then diluted with the sulfuric acid solution to approximately the same relative intensity, and absorption spectra were determined for each solution from $320 \mu$ to $1,000 \mu$ with a Beckman spectrophotometer. The absorption curves are presented in figure 2.

\section{Discussion of the Diphenylamine Test}

\subsection{Effect of Structure of the Aliphatic Nitrocom- pounds}

From the results presented in table 1, it is apparent that the aliphatic nitrocompounds may be divided into two general groups (table 2). (1) Nitrocompounds that have either a single hydrogen atom or three alkyl groups attached to the carbon bearing the nitrogroup give a positive reaction. (2) On the other hand, primary nitroparaffins, 2,2-dinitro- and 1,1,1-trinitrocompounds do not give the test. It is interesting to note that halogen apparently behaves in this test in the same manner as an alkyl group. 


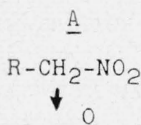

$$
\begin{aligned}
& \mathrm{R}-\mathrm{CH}=\mathrm{N}-\mathrm{OH} \\
& \downarrow \mathrm{H}_{2} \mathrm{SO}_{4} \\
& \mathrm{R}-\mathrm{CH}-\stackrel{\mathrm{NH}}{\mathrm{N}}-\mathrm{OH} \\
& \mathrm{OSO}_{3} \mathrm{H} \\
& \downarrow-\mathrm{H}_{2} \mathrm{O} \\
& \mathrm{R}-\mathrm{CH}-\mathrm{N}=\mathrm{O} \\
& 1 \\
& \mathrm{OSO}_{3} \mathrm{H} \\
& \downarrow \\
& \mathrm{R}-\mathrm{C}=\mathrm{N}-\mathrm{OH} \\
& \mathrm{OSO}_{3} \mathrm{H} \\
& \downarrow \mathrm{H}_{2} \mathrm{O} \\
& \mathrm{R}-\mathrm{C}-\mathrm{N}-\mathrm{OH} \\
& \mathrm{OH} \\
& \downarrow \mathrm{H}_{2} \mathrm{SO}_{4}+\mathrm{H}_{2} \mathrm{O} \\
& \mathrm{NH}_{2} \mathrm{OH} \cdot \mathrm{H}_{2} \mathrm{SO}_{4}+\mathrm{R}-\mathrm{COOH}
\end{aligned}
$$

A possible explanation for this behavior can be arrived at by considering the reaction of nitroparaffins in relatively concentrated sulfuric acid. It is believed [8] that sulfuric acid adds to the double bond of the aci-form of nitroparaffins (fig. 3) and the product loses water to form a nitroso derivative, which in the case of primary nitroparaffins (A), would enolize to a sulfated hydroxamic acid derivative. This, in turn, could hydrolyze through the hydroxamic acid to the carboxylic acid and hydroxylamine sulfate. Hydroxylamine not only does not give a positive diphenylamine test, but actually tends to inhibit the formation of the blue color. By an analogous series of reactions (fig. 3) one may consider that secondary (B) and tertiary (C) nitroparaffins could yield nitrous acid under similar con-

TABLE 2. Results of the diphenylamine test for aliphatic nitro compounds

\begin{tabular}{|c|c|}
\hline Positive & Negative \\
\hline $\mathrm{NO}_{2}$ & $\mathrm{R}-\mathrm{CH}_{2}-\mathrm{NO}_{2}$ \\
$\mathrm{R}-\mathrm{CH}-\mathrm{R}^{\prime}$ & $\mathrm{NO}_{2}$ \\
$\mathrm{R}^{\prime \prime}$ & $\mathrm{R}-\mathrm{C}-\mathrm{R}$ \\
$\mathrm{R}-\mathrm{C}-\mathrm{NO}_{2}$ & $\mathrm{NO}$ \\
$\mathrm{R}^{\prime \prime}$ & $\mathrm{R}$ \\
& $\mathrm{R}$ \\
& $\mathrm{C}\left(\mathrm{NO}_{2}\right)_{3}$ \\
\hline
\end{tabular}

$\mathrm{R}$, Alkyl; $\mathrm{R}^{\prime}$, alkyl, nitro, or halogen; $\mathrm{R}^{\prime \prime}$, alkyl or halogen; $\mathrm{R}^{\prime \prime \prime}$, alkyl or nitro.

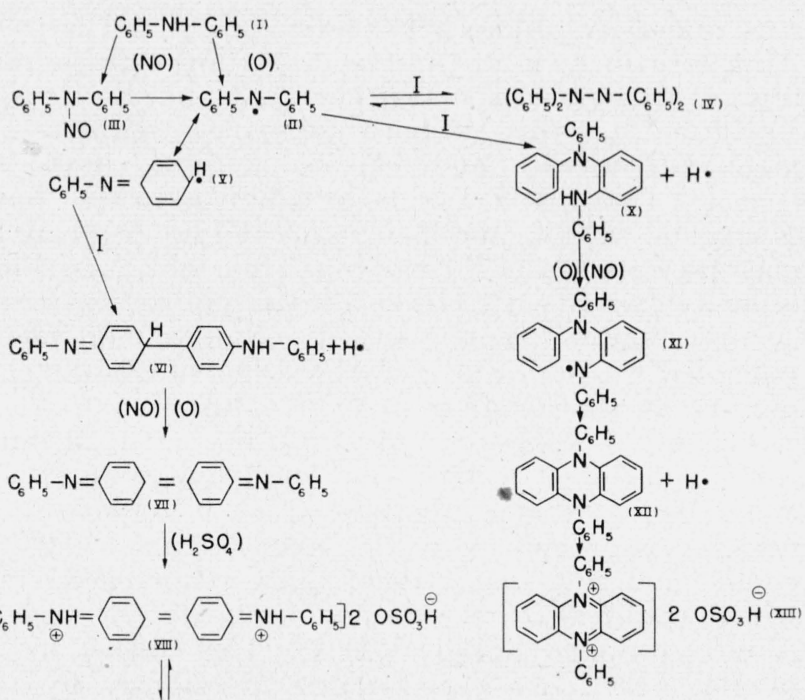

DIPHENYLBENZIDINE QUINHYDRONE

FIGURE 4. Electronic interpretation of the oxidation and nitrosation of diphenylamine.

ditions. Actual experimental support for the formation of nitrous acid or oxides of nitrogen was indicated by the fact that those nitrocompounds that gave a test by the direct method also gave it by the indirect method. Further substantiation was afforded by isolation of $N$-nitrosodiphenylamine from the reaction of a tertiary nitroparaffin with sulfuric acid, as described in section 2.3.

\subsection{Nature of Blue Products Formed}

In order to ascertain the nature of the blue color derived from diphenylamine, sulfuric acid solutions containing various oxidizing and nitrosating agents were prepared with this reagent, and spectroscopic curves were determined (fig. 2). The absorption curves obtained after either oxidation $(B, E$, and $G$ ) or nitrosation (A, C, D, F, and $\mathrm{H}$ ) of diphenylamine are quite similar. According to Kehrmann and his coworkers $[4,5]$, the blue color obtained by oxidation of diphenylamine in sulfuric acid is caused by a quinoidal immonium salt of diphenylbenzidine (VIII, fig. 4), in equilibrium with a hypothetical substance termed "diphenylbenzidine quinhydrone." In support of this hypothesis, they succeeded in isolating diphenylbenzidine in good yields by the zinc-dust reduction of their blue-colored products. Furthermore, Wieland and Gambarjan [7] were able to show that diphenylamine can be oxidized to tetraphenylhydrazine, which in turn could be rearranged in sulfuric acid to $N, N^{\prime \prime}$-diphenylbenzidine. In his earlier work, Wieland [1] had reported the isolation of $N, N^{\prime}$-diphenyldihydrophenazine (XII, fig. 4) from tetraphenylhydrazine in toluene and postulated that some such phenazine sulfate derivative as represented by formula XIII (fig. 4) may be responsible for the blue color in the diphenylamine test. Therefore, both $N, N^{\prime}$-diphenyldihydrophena- 
zine and $N, N^{\prime}$-diphenylbenzidine were synthesized. After treatment in sulfuric acid solution with sodium nitrite, they gave spectral curves $J$ and $K$, respectively. A mixture of both substances upon treatment with nitrite gave a curve, L, quite similar to curves A through H. Thus, it would seem that both phenazine sulfate and benzidine sulfate derivatives may be responsible for the blue color obtained from diphenylamine with either nitrosating or oxidizing agents. In addition, curve I, obtained for tetraphenylhydrazine, indicates that this substance also may be an intermediate in the reaction.

A possible explanation for the formation of the blue color is outlined in figure 4. Diphenylamine (I) on treatment with oxidizing agents, such as potassium nitrate, hydrogen peroxide, and sodium chlorate, could give the free radical diphenylnitrogen (II), which could also be obtained from (I) by way of $N$-nitrosodiphenylamine (III). The latter compound, which has been isolated previously by the action of sodium nitrite and hydrochloric acid on I, was also obtained from an aliphatic nitrocompound in this study (section 2.3). The free radical II, which is probably in equilibrium with tetraphenyl. hydrazine (IV), may be written as the paraquinoid form (V). This latter free radical may displace a parahydrogen atom of another molecule of diphenylamine (I), giving $N, N^{\prime}$-diphenylbenzidine (written as a monoquinoid structure VI), which, on further oxidation or nitrosation, may be converted by way of a diquinoid structure VII to a sulfate such as VIII.

The formation of a phenazine derivative may be explained as follows: The free radical diphenylnitro- gen (II) may displace an orthohydrogen atom from another molecule of diphenylamine, giving a derivative of $o$-phenylenediamine (X), which, by way of another free radical (XI), may be converted into $N, N^{\prime}$-diphenyldihydrophenazine (XII).

The results obtained by Kehrmann and Wieland, in conjunction with the spectral curves presented herein, seem to indicate that blue-colored derivatives of both phenazine and benzidine are probably involved in the diphenylamine test. The free radical interpretation is also supported by the fact that nitrosodiphenylamine dissolved in sulfuric acid gives a curve similar to those obtained from diphenylamine upon treatment with oxidizing or nitrosating agents; hence, nitrosodiphenylamine may be an intermediate when diphenylamine in sulfuric acid is treated with either sodium nitrite or aliphatic nitrocompounds.

\section{References}

[1] S. P. Mulliken, A method for the identification of pure organic compounds, p. 27 (John Wiley \& Sons, Inc., New York, N. Y., 1916).

[2] H. Wieland, Ann. 381, 210 (1911).

[3] H. Wieland, Ber. deut. chem. Ges. 46, 3296 (1913); 52, $886(1919)$

[4] F. Kehrmann and St. Micewicz, Ber. deut. chem. Ges. 45, 2641 (1912).

[5] F. Kehrmann and G. Roy, Ber. deut. chem. Ges. 55, 156 (1922).

[6] S. Wexman, Farm. Chilena 20, 299 (1946).

[7] H. Wieland and S. Gambarjan, Ber. deut. chem. Ges. 39, 1499 (1906).

[8] H. B. Hass and E. F. Riley, Chem. Rev. 32, 397 (1943).

Washington, June 13, 1952. 